\title{
Improving Influenza Vaccination Rates of High-Risk Inner-City Children Over 2 Intervention Years
}

Richard K. Zimmerman, $M D^{1,2}$

Alejandro Hoberman, $M D^{3}$

Mary Patricia Nowalk, PbD, RD

Chyongchiou J. Lin, PbD ${ }^{4,5}$

David P. Greenberg, $M D^{3}$

Stuart T. Weinberg, $M D^{6}$

Feng Shou Ko, MS ${ }^{7}$

Dwight E. Fox, DMD ${ }^{1}$

'Department of Family Medicine and Clinical Epidemiology, University of Pittsburgh

School of Medicine, Pittsburgh, $\mathrm{Pa}$

${ }^{2}$ Department of Behavioral and Community Health Sciences, University of Pittsburgh Graduate School of Public Health, Pittsburgh, $\mathrm{Pa}$

${ }^{3}$ Department of Pediatrics, University of Pittsburgh School of Medicine, Pittsburgh, $\mathrm{Pa}$

${ }^{4}$ Department of Radiation Oncology, University of Pittsburgh School of Medicine, Pittsburgh, $\mathrm{Pa}$

${ }^{5}$ Department of Health Policy and Management, University of Pittsburgh Graduate School of Public Health, Pittsburgh, Pa

${ }^{6}$ Vanderbilt University, Nashville, Tenn

${ }^{7}$ Department of Biostatistics, University of Pittsburgh Graduate School of Public Health, Pittsburgh, Pa

Conflicts of interest: At the time of study design and implementation, Dr. Greenberg was an employee of the University of Pittsburghi, from the time of manuscript preparation, he bas been employed by Sanofi Pasteur, Inc.

\section{CORRESPONDING AUTHOR}

Mary Patricia Nowalk, PhD, RD

Department of Family Medicine and

Clinical Epidemiology

University of Pittsburgh School of Medicine 3518 Fifth Ave

Pittsburgh, PA 15261

tnowalk@pitt.edu

\begin{abstract}
PURPOSE Influenza immunization rates among children with high-risk medical conditions are disappointingly low, and relatively few data are available on raising rates, particularly over 2 years. We wanted to determine whether interventions tailored to individual practice sites improve influenza immunization rates among high-risk children in inner-city health centers over 2 years.
\end{abstract}

METHOD A before-after trial to improve influenza immunization of children was conducted at 5 inner-city health centers (residencies and faith-based). Sites selected interventions from a menu (eg, standing orders, patient and clinician reminders, education) proved to increase vaccination rates, which were directed at children aged 2 to 17 years with high-risk medical conditions. Intervention influenza vaccination rates and 1 and 2 years were compared with those of the preintervention year (2001-2002) and of a comparison site.

RESULTS Influenza vaccination rates improved modestly from baseline (10.4\%) to $13.1 \%$ during intervention year 1 and to $18.7 \%$ during intervention year $2(P$ $<.001$ ), with rates reaching $31 \%$ in faith-based practices. Rates increased in all racial and age-groups and in Medicaid-insured children. The increase in rates was significantly greater in intervention health centers (8.3\%) than in the comparison health center $(0.7 \% ; P<.001)$. In regression analyses that controlled for demographic factors, vaccination status was associated with intervention year 1 (odds ratio $[\mathrm{OR}], 1.9 ; 95 \%$ confidence interval $[\mathrm{Cl}], 1.6-2.2)$ and with intervention year $2(\mathrm{OR}, 2.8 ; 95 \% \mathrm{Cl}, 2.3-3.4)$, as well as with practice type. Adolescents had lower vaccination rates than children 2 to 6 years old (OR, 0.6; $95 \% \mathrm{Cl}, 0.5-0.7)$.

CONCLUSIONS Tailored interventions selected from a menu of interventions modestly increased influenza vaccination rates over 2 years at health centers serving children from low-income families. We recommend this strategy for faith-based practices and residencies with 1 practice site, but further research is needed on multisite practices and to achieve higher influenza vaccination rates.

Ann Fam Med 2006;4:534-540. DOI: 10.1370/afm.612.

\section{INTRODUCTION}

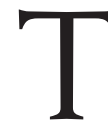

The Advisory Committee on Immunization Practices (ACIP) of the Centers for Disease Control and Prevention, the American Academy of Family Physicians (AAFP), and the American Academy of Pediatrics (AAP) recommend inactivated influenza vaccination for children aged 6 months through 17 years with high-risk medical conditions ${ }^{1-3}$ for several reasons. First, children with high-risk medical conditions bear a disproportionate share of the burden of hospitalizations and deaths because of influenza. ${ }^{4}$ For instance, among children aged 1 to 4 years, influenza-related hospitalization rates range from about 320 to 800 per 100,000 for those with high-risk conditions, compared with 86 to 186 per 100,000 for similarly aged healthy children. ${ }^{1,5,6}$ Second, because influenza 
infection circulates widely during influenza season, with annual influenza attack rates in preschool-aged children often ranging from $14 \%$ to $40 \%,{ }^{7-9}$ high-risk children are likely to be exposed. Third, vaccine efficacy among children with asthma has been reported as $22 \%$ to $54 \%$ among children aged 2 to 6 years and $60 \%$ to $78 \%$ among children aged 7 to 14 years. ${ }^{10}$

Despite the ACIP-AAFP-AAP recommendations, vaccination rates among high-risk children are disappointingly low. For instance, among children with asthma, vaccination rates have been reported at $9 \%$ to $25 \%{ }^{11,12}$ Studies designed to improve influenza vaccination rates have had moderate success. ${ }^{13-15}$ Although the Task Force on Community Preventive Services has published systematic reviews for age-based vaccine recommendations ${ }^{16}$ and for high-risk vaccination strategies for adults, ${ }_{1}^{17}$ it has not published a review of vaccinations for high-risk children, presumably because of lack of data. The goal of this study was to determine whether interventions selected from a menu and tailored to individual practice sites improve influenza immunization rates among high-risk children in innercity health centers over 2 years.

\section{METHODS}

\section{Site Descriptions}

We conducted a before-after trial with a comparison practice at inner-city health centers. Participating sites included 1 pediatric residency and faculty practice (pediatric residency), 2 family medicine residencies, and 2 faith-based community health centers (ie, centers whose mission is to show "God's love" by compassionate health care to all who come, regardless of ability to pay). Children were seen in 10 offices located in lowerincome neighborhoods throughout the City of Pittsburgh and in 1 nearby small, economically depressed city. Combined, the participating health centers serve a larger proportion of minority patients than is represented in the general population of the Pittsburgh metropolitan area (approximately 15\%). ${ }^{18}$ The comparison health center was a small family medicine residency site that was located in a lower-income neighborhood in the City of Pittsburgh and served a large proportion of minorities. This project was approved by the Institutional Review Boards of the University of Pittsburgh and Children's Hospital of Pittsburgh.

\section{Interventions}

Introductory meetings were held with representatives of nursing and medical staffs to present a menu of patient-, clinician-, and system-directed options to increase influenza immunizations among children aged 6 to 23 months and 2 to 17 years with high-risk conditions; this report focuses on the latter group. Intervention strategies presented to the health centers were derived from the Task Force for Community Preventive Services report on interventions proven to raise immunization rates, ${ }^{16}$ albeit in circumstances other than influenza vaccination of high-risk children. Interventions for each center were developed using ideas generated at these meetings and based on characteristics of each center's operation and patient population. Examples of interventions included establishing standing orders so that children could be vaccinated without seeing the physician, walk-in anytime influenza vaccinations, Saturday influenza vaccination clinics, and reminder e-mails sent to all clinicians about influenza vaccination (Table 1).

Investigators assisted with implementation, eg, designing, printing, and mailing a flyer to parents; procuring posters; and assisting with reminder telephone calls to parents. Investigators also held educational meetings for medical and nursing staffs. All centers received stipends of $\$ 3,000$ for participation in the research investigation to help defray the costs incurred for mailings, staffing influenza immunization clinics, telephone calls, and providing demographic and immunization data.

After intervention year 1, the investigators met with the staffs of each of the intervention health centers to review the interventions used and assess the perceived practicality and efficacy of each. These discussions served as the basis for developing the intervention for year 2. Health centers eliminated, added, modified, and maintained various strategies. Just before the beginning of the influenza vaccination season for intervention year 2, the investigators again met with staff at the sites to plan strategies, conduct staff and clinician educational sessions, provide posters and flyers, and assist with development of mailed reminders. During both intervention years, the investigators periodically contacted the health centers to offer support and address issues that may have arisen.

The comparison site was selected because of its similarity to other practices in terms of geographic location and patient characteristics. It was not contacted about this study until after intervention year 2 , and at that time its influenza vaccination rate for high-risk children was unknown. This site was not part of the tailored intervention effort; however, ongoing strategies for increasing immunization that were reported to the investigators by the lead physician at the comparison site included having an immunization champion and clinician education. During the 2003 2004 influenza vaccination season, in a campaign to increase adult immunizations, they created posters about influenza and adult immunizations, sent influenza vaccine mailings to Medicaid-insured families, 
Table 1. Site Characteristics and Strategies Used to Improve Influenza Vaccination Rates

\begin{tabular}{|c|c|c|c|c|c|c|c|c|c|c|}
\hline \multirow[b]{3}{*}{ Characteristics } & \multicolumn{5}{|c|}{ Intervention Year 1} & \multicolumn{5}{|c|}{ Intervention Year 2} \\
\hline & \multicolumn{5}{|c|}{ Site } & \multicolumn{5}{|c|}{ Site } \\
\hline & 1 & 2 & 3 & 4 & 5 & 1 & 2 & 3 & 4 & 5 \\
\hline \multicolumn{11}{|l|}{ Site } \\
\hline Type & PR & $F B$ & FB & FM & FM & PR & $F B$ & FB & FM & FM \\
\hline Number of offices & 5 & 2 & 1 & 1 & 1 & 5 & 2 & 1 & 1 & 1 \\
\hline Immunization tracking & EVR & EMR & Manual & EMR & Manual & EVR & EMR & Manual & $\begin{array}{c}\text { New } \\
\text { FMR }^{*}\end{array}$ & $\begin{array}{l}\text { New } \\
\text { FMR }\end{array}$ \\
\hline \multicolumn{11}{|l|}{ Strategy } \\
\hline \multicolumn{11}{|l|}{$\begin{array}{l}\text { Interventions to increase demand } \\
\text { for vaccines }\end{array}$} \\
\hline $\begin{array}{l}\text { Posters in waiting and examina- } \\
\text { tion rooms }\end{array}$ & $\checkmark$ & $\checkmark$ & $\checkmark$ & $\checkmark$ & $\checkmark$ & $\checkmark$ & $\checkmark$ & $\checkmark$ & $\checkmark$ & $\checkmark$ \\
\hline Letter or flier mailed to parent & $\checkmark$ & $\checkmark$ & $\checkmark$ & $\checkmark$ & $\checkmark$ & $\checkmark$ & $\checkmark$ & - & $\checkmark$ & - \\
\hline Telephone calls to parent & $\checkmark$ & - & - & - & $\checkmark$ & $\checkmark$ & - & - & - & - \\
\hline $\begin{array}{l}\text { Flier handed out at registration } \\
\text { during influenza season }\end{array}$ & - & - & - & - & - & - & - & - & - & $\checkmark$ \\
\hline \multicolumn{11}{|l|}{$\begin{array}{l}\text { Interventions to enhance access to } \\
\text { vaccination services }\end{array}$} \\
\hline $\begin{array}{l}\text { Walk-in flu shots during office } \\
\text { hours }\end{array}$ & $\checkmark$ & $\checkmark$ & $\checkmark$ & - & - & $\checkmark$ & $\checkmark$ & $\checkmark$ & - & - \\
\hline Special event flu shot clinics & $t$ & - & $\ddagger$ & - & - & $t$ & - & $\ddagger$ & - & - \\
\hline \multicolumn{11}{|l|}{$\begin{array}{l}\text { Physician or system-based } \\
\text { interventions }\end{array}$} \\
\hline Clinician education & $\checkmark$ & $\checkmark$ & $\checkmark$ & $\checkmark$ & $\checkmark$ & $\checkmark$ & $\checkmark$ & $\checkmark$ & $\checkmark$ & $\checkmark$ \\
\hline $\begin{array}{l}\text { Standing orders for nurses to } \\
\text { vaccinate }\end{array}$ & $\checkmark$ & $\checkmark$ & $\checkmark$ & $\checkmark$ & - & $\checkmark$ & $\checkmark$ & $\checkmark$ & $\checkmark$ & - \\
\hline $\begin{array}{l}\text { Physician educational reminder } \\
\text { e-mails }\end{array}$ & $\checkmark$ & $\checkmark$ & $\checkmark$ & $\checkmark$ & $\checkmark$ & - & - & - & - & - \\
\hline $\begin{array}{l}\text { Chart reminders: printed or hand- } \\
\text { written or EMR pop-up screen } \\
\text { or flag }\end{array}$ & $\checkmark$ & $\checkmark$ & - & - & - & - & $\checkmark$ & - & $\S$ & - \\
\hline Total number of interventions & 9 & 7 & 7 & 5 & 5 & 7 & 6 & 5 & 4 & 3 \\
\hline $\begin{array}{l}\text { Change in vaccination rate over } \\
2 \text { years (\%) }\end{array}$ & - & - & - & - & - & 8 & 11.3 & 15.6 & 28 & 13.3 \\
\hline \multicolumn{11}{|c|}{ Note: Interventions are categorized according to the scheme of the Task Force on Community Preventive Services. } \\
\hline \multicolumn{11}{|c|}{$\begin{array}{l}\mathrm{PR}=\text { pediatric residency; } \mathrm{FB}=\text { faith-based; } \mathrm{FM}=\text { family medicine residency; } \mathrm{EVR}=\text { electronic vaccine registry; } \mathrm{EMR}=\text { electronic medical record; manual }=\text { paper } \\
\text { charts; } \boldsymbol{V}=\text { used at site; }-=\text { not used at site. }\end{array}$} \\
\hline \multicolumn{11}{|c|}{$\begin{array}{l}\text { * Changed from dictated notes entered into EMR to direct physician entry into new EMR. } \\
\text { † Saturday. } \\
\text { F Weekdays during office hours. }\end{array}$} \\
\hline
\end{tabular}

held express influenza vaccination clinics, and instituted standing orders for adult vaccination.

\section{Eligibility Criteria}

We selected children aged 2 to17 years in 2002-2003 and 2003-2004 who had high-risk conditions and who were active patients of the practice; that is, they had been seen in the office at any time in the last year. High-risk medical conditions for which influenza vaccination is recommended include asthma and other chronic diseases of the respiratory system, sickle cell disease, human immunodeficiency virus infection, and diabetes. For the purposes of identifying high-risk children in computer systems, the following International Classification of Diseases, Ninth Revision, codes were used: 042, 042.9, 250.01, 277.00, 282.6, 282.60, 493, 493.0,
493.1, 493.9, 770.7, and 786.09. The comparison group for historical analysis was high-risk children aged 2 to 17 years who were active patients during the preintervention influenza season (2001-2002).

\section{Data Collection}

For those centers with electronic medical records (EMR) or electronic vaccine registries (EVR), data files containing the variables of interest were transferred to the investigators. For those centers without EMR or EVR, investigators gathered data by manual medical record reviews and entered the data into an electronic database using CASA immunization software (Centers for Disease Control and Prevention, Atlanta, Ga). Variables of interest included date of birth, race, sex, type of insurance, type of vaccine given, and dates of vac- 
cine administration. The influenza vaccination season was defined as October through February.

\section{Statistical Analysis}

Basing our analysis on the generalized linear model theory ${ }_{1}^{19}$ we used analysis of variance (ANOVA) for the binary outcome to compare influenza immunization rates between the preintervention and intervention periods by sex, race, age, and health insurance status and to compare the intervention sites with the concurrent control. In ANOVA calculations for preintervention and postintervention influenza immunization rates, interaction terms for practice type were not statistically significant; therefore, health centers were combined when testing for differences from the comparison site. We conducted logistic regression analyses with influenza vaccination status as the outcome based on the immunization data and demographic data available. Analyses were performed using SAS 8.2, (SAS Institute Inc, Cary, NC). Statistical significance was set at $P<.05$ for all tests.

\section{RESULTS}

\section{Demographics}

Table 2 displays the demographic characteristics of the intervention population. Most children were from economically disadvantaged families, as indicated by the proportion who were Medicaid insured, and this group overrepresented the minority population of this area. Distribution by sex was approximately equal, and there were slightly more children aged 7 to 12 years than in the younger and older age-groups. The population at the comparison health center was $45 \%$ to $49 \%$ female and $74 \%$ to $83 \%$ black, and most were Medicaid insured (70\%-75\%), depending on the year.

\section{Influenza Vaccination Rates}

Table 3 displays the vaccination rates from the preintervention year through the 2 intervention years. Overall, vaccination rates were $10.4 \%$ in 2001-2002, $13.1 \%$ in $2002-2003$, and $18.7 \%$ in 2003-2004 ( $P<.001)$. These rates increased in all racial groups and in insurance types (data not shown). Rates also increased significantly in all age-groups, although adolescents achieved the lowest final rates. As one can calculate from
Table 3, improvements in influenza vaccination rates were lowest in the pediatric residency $(6.9 \%)$, intermediate in the faith-based sites (14.3\%), and highest in the family medicine residency sites $(22.8 \%)$; however, baseline rates were lowest in the family medicine residency sites (4.2\%).

At the comparison site, vaccination rates were $42.0 \%$ in $2001-2002,41.1 \%$ in $2002-2003$, and $42.7 \%$ in 2003-2004 (not significant) (Figure 1). The change from 2001-2002 to 2002-2003 in overall influenza vaccination rate for the intervention sites vs the comparison site was significant $(2.7 \%$ vs $-0.9 \%, P<.001)$. The overall increase in rates from 2001-2002 to 2003-2004 was greater in intervention sites than the comparison site $(8.3 \%$ vs $0.7 \%, P<.001)$. The stepwise changes in rates over 2 years from 2001 to 2004, were also significantly different $(2.7 \%$ and $8.3 \%$ for intervention sites vs $-0.9 \%$ and $0.7 \%$ for the comparison site, $P<.001)$.

Table 4 provides the determinants of vaccination from the logistic regression model, controlling for known demographic factors. Intervention year and type of practice had the highest odds ratios. The likelihood of vaccination during intervention year 1 was nearly twice as high as preintervention (odds ratio [OR], 1.9) and 3 times as high during intervention year 2 (OR, 2.8). Vaccination was higher at the faith-based centers $(O R, 3.0)$ and the pediatric residency $(O R$, 1.7) than at the family medicine residencies. Likelihood of vaccination was significantly lower among

\begin{tabular}{|c|c|c|c|c|}
\hline Variable & $\begin{array}{c}\text { Preintervention } \\
(\mathrm{n}=2,438) \\
\text { No. }(\%)\end{array}$ & $\begin{array}{c}\text { Intervention } \\
\text { Year } 1 \\
\text { (n = } 2,935) \\
\text { No. }(\%)\end{array}$ & $\begin{array}{c}\text { Intervention } \\
\text { Year } 2 \\
\text { (n = 3,311) } \\
\text { No. }(\%)\end{array}$ & $\begin{array}{c}P \\
\text { Value* }\end{array}$ \\
\hline Sex & & & & .320 \\
\hline Male & $1,334(54.7)$ & $1,664(56.7)$ & $1,844(55.7)$ & \\
\hline Female & $1,000(41.0)$ & $1,171(39.9)$ & $1,352(40.8)$ & \\
\hline Unknown & $104(4.3)$ & $100(3.4)$ & 115 (3.5) & \\
\hline Race & & & & $<.001$ \\
\hline Black & 1,107 (45.4) & $1,224(41.7)$ & $1,227(37.1)$ & \\
\hline White/other & $312(12.8)$ & 320 (10.9) & 385 (11.6) & \\
\hline Unknown & $1,019(41.8)$ & 1,391 (47.4) & 1,699 (51.3) & \\
\hline Insurance type & & & & $<.001$ \\
\hline Private & 305 (12.5) & $299(10.2)$ & $430(13.0)$ & \\
\hline Medicaid & $1,177(48.3)$ & $1,626(55.4)$ & $1,863(56.3)$ & \\
\hline Self-pay & $59(2.4)$ & $100(3.4)$ & $100(3.0)$ & \\
\hline Not reported & $897(36.8)$ & $910(31.0)$ & $918(27.7)$ & \\
\hline Age, years & & & & $<.001$ \\
\hline $2-6$ & 774 (31.7) & $1,126(38.4)$ & $1,121(33.9)$ & \\
\hline $7-12$ & $1,038(42.6)$ & 937 (31.9) & $1,258(38.0)$ & \\
\hline $13-17$ & $626(25.7)$ & $872(29.7)$ & $932(28.1)$ & \\
\hline
\end{tabular}




\begin{tabular}{|c|c|c|c|c|}
\hline \multirow[b]{2}{*}{ Variable } & \multicolumn{3}{|c|}{ Vaccination Rate (\%) } & \multirow[b]{2}{*}{$P$ Value } \\
\hline & $\begin{array}{l}\text { Preintervention } \\
(\mathrm{n}=2,438)\end{array}$ & $\begin{array}{c}\text { Intervention } \\
\text { Year } 1 \\
(n=2,935)\end{array}$ & $\begin{array}{c}\text { Intervention } \\
\text { Year } 2 \\
(n=3,311)\end{array}$ & \\
\hline \multicolumn{5}{|l|}{ Sex } \\
\hline Male & 10.7 & 12.0 & 18.4 & $<.001$ \\
\hline Female & 11.4 & 14.9 & 18.8 & $<.001$ \\
\hline Unknown & 14.6 & 10.0 & 22.6 & .015 \\
\hline \multicolumn{5}{|l|}{ Race } \\
\hline Black & 9.9 & 12.1 & 19.6 & $<.001$ \\
\hline White/other & 17.9 & 18.1 & 25.7 & .001 \\
\hline Unknown & 10.5 & 11.1 & 16.5 & $<.001$ \\
\hline \multicolumn{5}{|l|}{ Age, years } \\
\hline $2-6$ & 14.3 & 14.0 & 19.0 & .002 \\
\hline $7-12$ & 10.4 & 12.7 & 20.7 & $<.001$ \\
\hline $13-17$ & 8.6 & 9.5 & 15.8 & $<.001$ \\
\hline \multicolumn{5}{|l|}{ Type of practice } \\
\hline Pediatric residency & 11.2 & 12.5 & 18.1 & $<.001$ \\
\hline $\begin{array}{l}\text { Family medicine } \\
\text { residencies }\end{array}$ & 4.2 & 8.1 & 27.0 & .002 \\
\hline $\begin{array}{l}\text { Faith-based health } \\
\text { centers }\end{array}$ & 16.7 & 18.2 & 31.0 & .020 \\
\hline Total & 10.4 & 13.1 & 18.7 & $<.001$ \\
\hline \multicolumn{5}{|c|}{ * Analysis of variance for the binary outcome. } \\
\hline \multicolumn{5}{|c|}{$\begin{array}{l}\text { Preintervention year }=2001-2002 \text {; intervention year } 1=\text { October 2002-February 2003; intervention } \\
\text { year } 2=\text { October } 2003 \text {-February } 2004 .\end{array}$} \\
\hline
\end{tabular}

adolescents than among the youngest children (aged 2 to 6 years), and it was significantly higher among privately insured children than among those on Medicaid and among white children compared with black children.

\section{DISCUSSION}

Our interventions to increase immunization in this high-risk population have resulted in significant improvements ${ }_{i}$ however, their success as measured by vaccination rates is modest. Although the Task Force on Community Preventive Services has conducted systematic reviews for age-based vaccine recommendations ${ }^{16}$ and for high-risk vaccinations for adults, ${ }_{17}^{17}$ it has not published a review of vaccination strategies for high-risk children, presumably because of lack of data. In fact, the Task Force found insufficient evidence for most types of interventions for high-risk adults; only clinician reminders and interventions in combination have sufficient evidence to be recommended for adults. Specifically, the Task Force rec-

Figure 1. Influenza vaccination rates of children aged 2 to 17 years with chronic medical conditions.

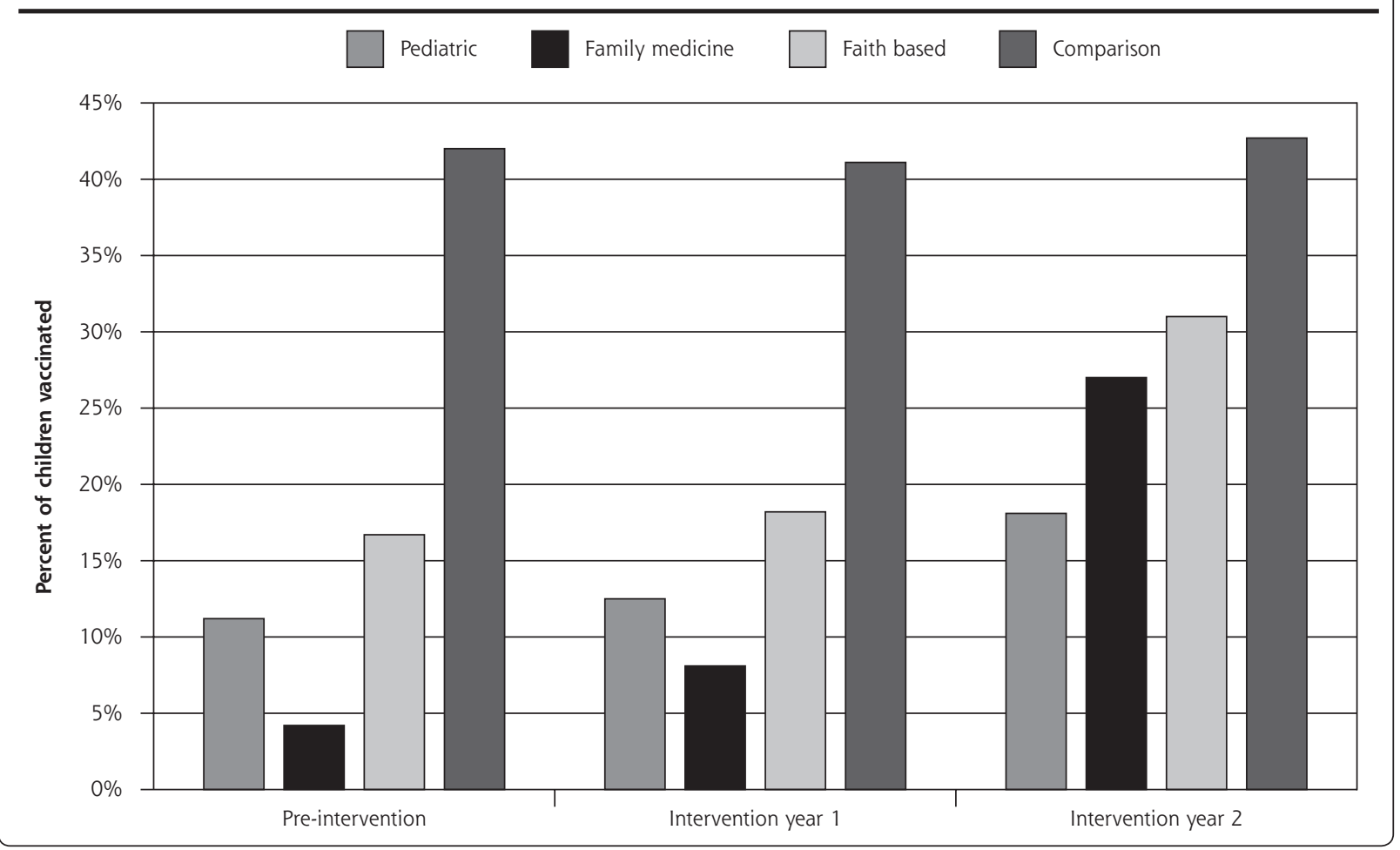




\begin{tabular}{|c|c|c|}
\hline Variable & $\begin{array}{l}\text { Odds Ratio } \\
(95 \% \mathrm{Cl})\end{array}$ & $\begin{array}{c}P \\
\text { Value }\end{array}$ \\
\hline \multicolumn{3}{|l|}{ Age (reference $=2-6$ years) } \\
\hline $7-12$ years & $0.9(0.8-1.1)$ & .418 \\
\hline $13-17$ years & $0.5(0.4-0.6)$ & $<.001$ \\
\hline \multicolumn{3}{|l|}{ Race (reference = black) } \\
\hline White/other & $1.5(1.2-1.8)$ & $<.001$ \\
\hline Unknown & $0.8(0.7-0.9)$ & $<.001$ \\
\hline \multicolumn{3}{|l|}{ Sex (reference $=$ female) } \\
\hline Male & $0.9(0.8-0.99)$ & .047 \\
\hline Unknown & $1.3(0.9-1.8)$ & .130 \\
\hline \multicolumn{3}{|l|}{$\begin{array}{l}\text { Insurance type } \\
\text { (reference = Medicaid) }\end{array}$} \\
\hline Private & $1.4(1.1-1.6)$ & .002 \\
\hline Self-pay & $0.8(0.5-1.1)$ & .196 \\
\hline Not reported & $1.0(0.8-1.2)$ & .977 \\
\hline \multicolumn{3}{|c|}{ Year (reference $=$ preintervention) } \\
\hline Intervention year 1 & $1.9(1.6-2.2)$ & $<.001$ \\
\hline Intervention year 2 & $2.8(2.3-3.4)$ & $<.001$ \\
\hline \multicolumn{3}{|c|}{$\begin{array}{l}\text { Type of practice (reference = family } \\
\text { medicine residency) }\end{array}$} \\
\hline Pediatric residency & $1.7(1.1-2.5)$ & .013 \\
\hline Faith-based health centers & $3.0(1.9-5.0)$ & $<.001$ \\
\hline
\end{tabular}

ommends a menu approach for high-risk adults, which is similar to the approach herein. One intervention study showed that reminder and recall systems increased vaccination rates for children with asthma from $5 \%$ to $32 \%,{ }^{13}$ and another intervention offering vaccination plus education in the emergency department increased rates to $57 \%$ compared with $36 \%$ for education only. ${ }^{14}$ A more recent study using reminder and recall systems in private practices that participate in an immunization registry achieved a vaccination rate of $42 \%$ compared with $25 \%$ among controls. ${ }^{15}$ This study adds to the sparse literature on the topic and, to our knowledge, is the first study to (1) use tailored interventions and a menu approach, and (2) be conducted over 2 years, thereby limiting the year-to-year variability in rates.

In designing this study, we were influenced by indepth analyses of barriers to prevention by Crabtree et $\mathrm{al}_{1}{ }^{20}$ Miller et $\mathrm{al}_{1}{ }^{21}$ and Stange et $\mathrm{al}_{1}{ }^{22}$ who point out the considerable complexity and diversity in primary care practices and the importance of understanding the internal operating models and values of the practice. They and others suggest the need to tailor interventions to each practice to enhance the likelihood of success and of their continued use. ${ }^{20,23}$ In previous work involving other indications for influenza vaccine, we have found tailored interventions useful in increasing age-based vaccination rates in the inner city. ${ }^{24,25}$
Thus, we encouraged interventions tailored to the health center to account for the diversity in office cultures, patient cultures, and race. The faith-based practices achieved the highest rates and were associated with the highest likelihood of vaccination in the regression model. A review of Table 1 shows that all sites used interventions to increase demand, yet the faith-based sites used these approaches less frequently. In contrast, those sites doing best in regression analyses more frequently used interventions to increase access, such as special-event vaccine clinics, as well reminders to the clinicians and standing orders. It is therefore apparent that one size does not fit all with regard to the selection of strategies to improve influenza immunization rates in this population.

Several reasons might be suggested for the modest increases in vaccination rates. In this real-world study, other changes were occurring. At the pediatric residency for instance, several transitions occurred during the study, including the loss of a head nurse and a change in institutional affiliation. The family medicine residencies were also undergoing transitions that included switching from a paper to an electronic medical record at one health center and changing the brand of electronic medical records at another (electronic records may ultimately enhance rates, but the time of transition may be problematic). The faith-based health centers underwent fewer changes and as a group achieved higher rates at $31 \%$.

This study was occurring at the time that encouragement to vaccinate 6 - to 23 -month-old children was being promoted, and concentration on the younger children might have distracted attention from the high-risk children. Moreover, using medical conditions to recommend vaccination has never proved highly successful, as seen by the modest influenza vaccination rates for adults with high-risk conditions; indeed, one reason for lowering the age of routine adult vaccination from 65 to 50 years was to capture more individuals with high-risk conditions. We believe that the issue of vaccination for children with chronic medical conditions needs further qualitative and quantitative research, particularly in an effort to increase rates to more than $40 \%$.

We found that immunization rates were lower in adolescents, which may reflect their decreased interactions with the medical system. This situation may require interventions particularly targeted to older children, such as after-school immunization clinics or influenza vaccination coupled with asthma medication refills.

\section{Strengths and Limitations}

This multisite intervention targeted a hard-to-reach group of impoverished, largely minority children attending a variety of inner-city health centers over 2 
years, not just 1 year as is more typically reported in the medical literature. During those 2 years, interventions were tailored and refined to suit the capacities of the individual centers. Clinically meaningful and statistically significant, but variable, increases in rates occurred. This real-world experience occurred during a time of many transitions that were unrelated to our study but that may have diverted attention from the administration and documentation of influenza immunization.

A limitation is the design as a before and after intervention with a concurrent comparison group instead of a randomized trial. Another limitation is the moderate level of racial and other demographic data, which was the result of our dependence on administrative data sets from the health centers dictated by Health Insurance Portability and Accountability Act; we had no control over the completeness of such data. ${ }^{26}$

Tailored interventions modestly raise influenza immunization rates over 2 years for children aged 2 to 17 years who have high-risk medical conditions. Continual refinement of the strategies based on success of these interventions and attention to individual office culture may help to further improve rates.

\section{To read or post commentaries in response to this article, see it} online at http://www.annfammed.org/cgi/content/full/4/6/534.

Key words: Influenza vaccines; health services research; immunizations/ in infancy and childhood; infectious diseases

Submitted August 31, 2005; submitted, revised, February 13, 2006; accepted March 4, 2006.

Funding support: This study was made possible through a cooperative agreement between the Centers for Disease Control and Prevention and the Association of Teachers of Preventive Medicine, award number TS894; and the EXPORT Health Project at the Center for Minority Health, University of Pittsburgh Graduate School of Public Health, NIH/NCMHC grant No. P60 MD-000-207.

Disclaimer: The contents of this report are the responsibility of the authors and do not necessarily reflect the official views of the Centers for Disease Control and Prevention, the Association of Teachers of Preventive Medicine, or the Center for Minority Health.

\section{References}

1. Bridges CB, Fukuda K, Uyeki TM, Cox NJ, Singleton JA. Prevention and control of influenza. Recommendations of the Advisory Committee on Immunization Practices (ACIP). MMWR Recomm Rep. 2002:51:1-31.

2. Reduction of the influenza burden in children. Pediatrics. 2002;110:1246-1252.

3. Zimmerman RK. Recommended childhood and adolescent immunization schedule, United States, 2003 and update on childhood immunizations. Am Fam Physician. 2003;67:188, 190, 195-186.

4. Harper SA, Fukuda K, Uyeki TM, Cox NJ, Bridges CB. Prevention and control of influenza: recommendations of the Advisory Committee on Immunization Practices (ACIP). MMWR Recomm Rep. 2004:53:1-40.
5. Neuzil KM, Mellen BG, Wright PF, Mitchel EF, Jr., Griffin MR. The effect of influenza on hospitalizations, outpatient visits, and courses of antibiotics in children. N Engl J Med. 2000;342:225-231.

6. Neuzil KM, Wright PF, Mitchel EF, Jr., Griffin MR. The burden of influenza illness in children with asthma and other chronic medical conditions. J Pediatr. 2000;137:856-864.

7. Sullivan KM, Monto AS, Longini IM, Jr. Estimates of the US health impact of influenza. Am J Public Health. 1993;83:1712-1716.

8. Glezen WP. Considerations of the risk of influenza in children and indications for prophylaxis. Rev Infect Dis. 1980;2:408-420.

9. Glezen WP, Taber LH, Frank AL, Gruber WC, Piedra PA. Influenza virus infections in infants. Pediatr Infect Dis J. 1997;16:1065-1068.

10. Sugaya N, Nerome K, Ishida M, et al. Efficacy of inactivated vaccine in preventing antigenically drifted influenza type $A$ and wellmatched type B. JAMA. 1994;272:1122-1126.

11. Kramarz P, DeStefano F, Gargiullo PM, et al. Influenza vaccination in children with asthma in health maintenance organizations. Vaccine Safety Datalink Team. Vaccine. 2000;18:2288-2294.

12. Chung EK, Casey R, Pinto-Martin JA, Pawlowski NA, Bell LM. Routine and influenza vaccination rates in children with asthma. Ann Allergy Asthma Immunol. 1998;80:318-322.

13. Gaglani M, Riggs M, Kamenicky C, Glezen WP. A computerized reminder strategy is effective for annual influenza immunization of children with asthma or reactive airway disease. Pediatr Infect Dis J. 2001;20:1155-1160.

14. Pappano D, Humiston S, Goepp J. Efficacy of a pediatric emergency department-based influenza vaccination program. Arch Pediatr Adolesc Med. 2004:158:1077-1083.

15. Daley MF, Barrow J, Pearson K, et al. Identification and recall of children with chronic medical conditions for influenza vaccination. Pediatrics. 2004;113:e26-33.

16. Recommendations regarding interventions to improve vaccination coverage in children, adolescents, and adults. Task Force on Community Preventive Services. Am J Prev Med. 2000;18:92-96.

17. Recommendations to improve targeted vaccination coverage among high-risk adults. Am J Prev Med. 2005;28:231-237.

18. Table DP-1 Profile of general demographic characteristics: 2000. Geographic area: Allegheny County, Pennsylvania. US Census Bureau; 2001.

19. McCullage P, Nelder J. Generalized Linear Models. 2nd ed. London: Chapman and Hall; 1989.

20. Crabtree BF, Miller WL, Aita VA, Flocke SA, Stange KC. Primary care practice organization and preventive services delivery: a qualitative analysis. J Fam Pract. 1998;46:403-409.

21. Miller WL, Crabtree BF, McDaniel R, Stange KC. Understanding change in primary care practice using complexity theory. J Fam Pract. 1998;46:369-376.

22. Stange KC, Zyzanski SJ, Jaen CR, et al. Illuminating the 'black box'. A description of 4454 patient visits to 138 family physicians. J Fam Pract. 1998:46:377-389.

23. Greco PJ, Eisenberg JM. Changing physicians' practices. $N$ Engl Med. 1993;329:1271-1273.

24. Zimmerman RK, Nowalk MP, Raymund M, et al. Tailored interventions to increase influenza vaccination in neighborhood health centers serving the disadvantaged. Am J Public Health. 2003;93:1699-1705.

25. Zimmerman RK, Hoberman A, Nowalk MP, et al. Feasibility of influenza immunization for inner-city children aged 6 to 23 months. Am J Prev Med. 2004;27:397-403.

26. Zimmerman RK. Lowering the age for routine influenza vaccination to 50 years: AAFP leads the nation in influenza vaccine policy. American Academy of Family Physicians. Am Fam Physician. 1999:60:2061-2066, 2069-2070. 